Current Issues In Tourism

August 2019, Volume 22 Issue 13 Pages 1523-1525

https://doi.org/10.1080/13683500.2018.1449192

https://archimer.ifremer.fr/doc/00505/61642/

\title{
Pets at ecotourism destinations: cute mascot or trojan horse?
}

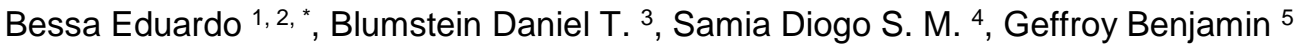

1 Univ Brasilia, Life \& Earth Sci Area, FUP, Brasilia, DF, Brazil.

2 Univ Brasilia, Grad Program Ecol, Biol Inst, Brasilia, DF, Brazil.

3 Univ Calif Los Angeles, Dept Ecol \& Evolutionary Biol, Los Angeles, CA USA.

4 Univ Sao Paulo, Biosci Inst, Dept Ecol, Sao Paulo, Brazil.

${ }^{5}$ Univ Montpellier, CNRS, IRD, IFREMER,MARBEC, Palavas Les Flots, France.

*Corresponding author : Eduardo Bessa, email address : profbessa@unb.br

\begin{abstract}
:
Alien species are threatening native fauna worldwide and cats and dogs have well-documented deleterious impacts on wildlife. Ecotourism operators often live and raise their pets in natural reserves. Here we discuss how pets add to the list of potential negative impacts of ecotourism and provide recommendations to control or attenuate such impacts.
\end{abstract}

Keywords : Cat, conservation, dog, invasive species, tourism 
Invasive species are considered the second most important cause of human-induced species extinction, closely behind habitat destruction (Bellard et al., 2016). Two of the most often introduced species are dogs and cats. In the US alone, there are an estimated 89.7 million dogs and 94.2 million cats living with humans (American Pet Products Association [APPA], 2018). Worldwide, there are likely billions of dogs in around 60\% of homes (APPA, 2018). However, cats and dogs and ecotourism impacts have been a neglected correlation.

It is generally accepted that cats are a threat to native species, especially birds, reptiles and small mammals. In the US alone, cats are estimated to kill as many as 3 billion birds and 20 billion mammals per year (Loss et al., 2013). In Australia, cats kill about 377 million of birds each year, among which $99 \%$ are native species (Woinarski et al., 2017). While the effect is most pronounced on ground dwelling 'critical weight range species' in arid areas (Johnson \& Isaac, 2009), cats are effective predators and may consume wild prey as big as $4 \mathrm{~kg}$ (Fancourt, 2015). On islands, cats are responsible for the extinction of at least 33 endemic species (Nogales et al., 2013). Cats have been reported as predators of an endangered insular bat (Roch, 2015), a threatened sea cormorant (Muzafar et al., 2013) and 63 other species (Doherty et al., 2016).

Dogs also are responsible for at least 11 extinctions and reducing population size of 188 species, effectively threatening their survival (Doherty et al., 2017). In Chile, dogs' predatory effects have modified a cervid's distribution (Silva-Rodriguez and Sieving, 2012). In Brazil, dogs negatively impact more than half the endangered vertebrate species (Lessa et al., 2016). In Australia, hiking trails where people are permitted to walk dogs have fewer birds than trails where dogs are banned (Banks and Bryant, 2007). Together, our two most common pets are responsible for declines 
in population sizes, and, in extreme cases, extinction of species. Nevertheless, there has not been many attempts put pets' negative impacts into context.

While cats and dogs are key drivers of faunal extinction by predation, they have other deleterious effects: they may compete with or disturb native wildlife, introduce diseases into wild populations, facilitate other invasions or hybridize with native species (Hughes and MacDonald, 2013; Medina et al., 2014). In Brazil, competition and disturbance by dogs on native fauna yield more deleterious effects than predation (Lessa et al., 2016). Dogs and cats (in addition to Norway rats) introduced trypanosome-transmitting fleas into Christmas Island, Australia, which drove a native rodent to extinction (Wyatt et al., 2008). Invasive cats hybridizing with Scottish wild cats increased its extinction risk (Kitchener et al., 2005). And, dogs can potentially hybridize with Iberian and Ethiopian wolves, coyotes, African wild dogs, and golden and black-backed jackals (Leonard et al., 2014).

Pets in nature-tourism areas add to the extensive list of ecotourism's impacts on wildlife (Blumstein et al., 2017). Clearly, well-controlled pets will have less of an impact than feral dogs and cats (Loss et al., 2013). Nevertheless, stray housecats are the main source of feral cats, and pet cats left to roam outside will have negative impacts.

Most ecotourists are well informed of the potential consequences that come with bringing their own pets into natural areas, but this information has to reach all travellers (Carr \& Cohen, 2009). In highly visited places, such as the Galapagos, communication surrounding the risks associated with pets is well known and pets are officially prohibited (Padilla et al., 2018). Despite that, in small natural areas, or in locations with less informed managers, operators may own cats and dogs as we have 
personally observed in many locations. In Table 1 we include a list of recommendations for dealing with these animals.

[Please insert Table 1 near here]

Identifying and managing domestic pets around ecotourism areas has not been fully recognized as a cost of ecotourism, creating a gap in the literature about tourism impacts. The efficacy of these management suggestions must be studied, but if effective, they may reduce yet another cost of ecotourism. By doing so, we may be able to better use ecotourism to preserve biodiversity which, ultimately, is one of its primary goals. The same way that subsistence hunting is banned in ecotourism areas, we believe that pet ownership should be strictly controlled.

\section{Acknoledgements}

We would like to thank Diana Agudelo for inspiring the initial idea for this paper and two anonymous reviewers for their suggestions.

\section{References}

American Pet Products Association. (2014). APPA National Pet Owners Survey Statistics: Pet ownership and annual expenses. 2013-2014 Survey. Retrieved on January 11, 2018 from http://www.americanpetproducts.org/pubs_survey.asp.

Banks, P. B., \& Bryant, J. V. (2007). Four-legged friend or foe? Dog walking displaces native birds from natural areas. Biology letters, 3(6), 611-613.

Bellard, C., Cassey, P., \& Blackburn, T. M. (2016). Alien species as a driver of recent extinctions. Biology Letters, 12(2), 20150623.

Blumstein, D. T., Geffroy, B., Samia, D. S., \& Bessa, E. (2017). Ecotourism's Promise and Peril. Springer, Cham. 
Carr, N., \& Cohen, S. (2009). Holidaying with the family pet: No dogs allowed! Tourism and Hospitality Research, 9(4), 290-304.

Dickman, C. R., \& Newsome, T. M. (2015). Individual hunting behaviour and prey specialisation in the house cat Felis catus: implications for conservation and management. Applied Animal Behaviour Science, 173, 76-87.

Doherty, T. S., Dickman, C. R., Glen, A. S., Newsome, T. M., Nimmo, D. G., Ritchie, E. G., ... \& Wirsing, A. J. (2017). The global impacts of domestic dogs on threatened vertebrates. Biological Conservation, 210, 56-59.

Doherty, T. S., Glen, A. S., Nimmo, D. G., Ritchie, E. G., \& Dickman, C. R. (2016). Invasive predators and global biodiversity loss. Proceedings of the National Academy of Sciences USA, 113(40), 11261-11265.

Fancourt, B. A. (2015). Making a killing: photographic evidence of predation of a Tasmanian pademelon (Thylogale billardierii) by a feral cat (Felis catus). Australian Mammalogy, 37(1), 120-124.

Hughes, J., \& Macdonald, D. W. (2013). A review of the interactions between freeroaming domestic dogs and wildlife. Biological Conservation, 157, 341-351.

Johnson, C. N., \& Isaac, J. L. (2009). Body mass and extinction risk in Australian marsupials: the 'Critical Weight Range' revisited. Austral Ecology, 34(1), 35-40.

Kitchener, A. C., Yamaguchi, N., Ward, J. M., \& Macdonald, D. W. (2005, August). A diagnosis for the Scottish wildcat (Felis silvestris): a tool for conservation action for a critically-endangered felid. Animal Conservation, 8(3), 223-237

Leonard, J. A., Echegaray, J., Randi, E., Vilà, C., \& Gompper, M. E. (2014). Impact of hybridization with domestic dogs on the conservation of wild canids. In: M. E. Gomper (Ed.), Free-ranging dogs and wildlife conservation (pp. 170-184). Oxford: Oxford University Press. 
Lessa, I., Guimarães, T. C. S., de Godoy Bergallo, H., Cunha, A., \& Vieira, E. M. (2016). Domestic dogs in protected areas: a threat to Brazilian mammals? Natureza \& Conservação, 14(2), 46-56.

Loss, S. R., Will, T., \& Marra, P. P. (2013). The impact of free-ranging domestic cats on wildlife of the United States. Nature Communications, 4, 1396.

Medina, F. M., Bonnaud, E., Vidal, E., \& Nogales, M. (2014). Underlying impacts of invasive cats on islands: not only a question of predation. Biodiversity and Conservation, 23(2), 327-342.

Muzaffar, S. B., Benjamin, S., \& Gubiani, R. (2013). The impact of fox and feral cat predation on the population viability of the threatened, endemic Socotra cormorant on Siniya Island, United Arab Emirates. Marine Ornithology, 41, 171-177.

Nogales, M., Vidal, E., Medina, F. M., Bonnaud, E., Tershy, B. R., Campbell, K. J., \& Zavaleta, E. S. (2013). Feral cats and biodiversity conservation: the urgent prioritization of island management. Bioscience, 63(10), 804-810.

Padilla L.R., Gottdenker N., Deem S.L. \& Cruz M. (2018) Domestic and peridomestic animals in Galapagos: health policies and practices. In: P. Parker (Ed.) Disease Ecology. Social and Ecological Interactions in the Galapagos Islands (pp. 269291). Cham: Springer.

Rocha, R. (2015). Look what the cat dragged in: Felis silvestris catus as predators of insular bats and instance of predation on the endangered Pipistrellus maderensis. Barb, 8(1), 18-21.

Silva-Rodríguez, E. A., \& Sieving, K. E. (2012). Domestic dogs shape the landscapescale distribution of a threatened forest ungulate. Biological Conservation, 150(1), 103-110. 
Winter, L. (2004). Trap-neuter-release programs: the reality and the impacts. Journal of the American Veterinary Medical Association, 225(9), 1369-1376.

Woinarski, J. C. Z., Murphy, B. P., Legge, S. M., Garnett, S. T., Lawes, M. J., Comer, S., ... \& Paton, D. (2017). How many birds are killed by cats in Australia? Biological Conservation, 214, 76-87.

Wyatt, K. B., Campos, P. F., Gilbert, M. T. P., Kolokotronis, S. O., Hynes, W. H., DeSalle, R., ... \& Greenwood, A. D. (2009). Correction: Historical mammal extinction on Christmas island (Indian ocean) correlates with introduced infectious disease. PLoS ONE, 4(1), 10.1371. 
Table 1. Recommendations to avoid pet-induced impacts on ecotourism areas.

- Ecotourism operators living or working in natural areas should not bring their pets.

- Cats and dogs in natural areas should be neutered.

- When banning is not possible, bells should be placed on pets' collars.

- Pets should not be left wandering free and unattended in natural areas (Winter 2004).

- Pets should be kept well-fed.

- Pets should be vaccinated and dewormed regularly.

- Special attention should be given to large, unneutered tom cats, which often specialize in wild prey (Moseby et al. 2015).

- Consider catching and removing high-risk individuals (Dickman and Newsome 2015), or, on islands, all individuals (Nogales et al. 2013). 